\title{
Helium isotope analyses of volcanic gases using a multi-turn time-of-flight mass spectrometer
}

\author{
YUKI HATTORI AND HIROCHIKA SUMINO
}

The University of Tokyo

Presenting Author: yukihatt2525@g.ecc.u-tokyo.ac.jp

Helium isotope ratio $\left({ }^{3} \mathrm{He} /{ }^{4} \mathrm{He}\right.$ ratio) shows different values in geochemical reservoirs such as the atmosphere, crust, and mantle. ${ }^{3} \mathrm{He} /{ }^{4} \mathrm{He}$ ratios of volcanic gases vary between magmatic (up to $1.1 \times 10^{-5}$ or lower) and crustal (less than $1 \times 10^{-7}$ ) values. When magma becomes active, ${ }^{3} \mathrm{He} /{ }^{4} \mathrm{He}$ ratio of volcanic gas may increase due to the increased contribution of magmatic helium. Therefore, ${ }^{3} \mathrm{He} /{ }^{4} \mathrm{He}$ ratio of volcanic gas has the potential as a monitoring tool of volcanic activity. Although continuous analysis of volcanic gas is necessary to monitor volcanic activity, it is difficult because a large magnet-sector type mass spectrometer is currently used to analyze helium isotopes due to requirements for mass resolution and sensitivity.

We have been developing a new technique of noble gas analysis using a portable multi-turn time-of-flight mass spectrometer (MULTUM) ${ }^{[1,}$ 2]. The high mass resolution achieved by a MULTUM is more than enough to distinguish ${ }^{3} \mathrm{He}^{+}$from $\mathrm{HD}^{+}$. However, the sensitivity of a normal MULTUM was far lower than the requirement to analyze noble gases in volcanic gas because most of noble gas molecules admitted to the spectrometer were pumped out by vacuum pumps directly connected to the spectrometer before ionized. Therefore, we installed valves between the spectrometer and the vacuum pumps to operate the mass spectrometer while it is isolated from the pumps. In addition, the ion counting method was introduced for signal processing of the secondary electron multiplier to detect weak signals of ${ }^{3} \mathrm{He}$ ions.

As a result, a significant number of ${ }^{3} \mathrm{He}$ ions were detected during analyses of volcanic gas samples. Besides, we investigated the pressure conditions, which enable accurate measurement of ${ }^{3} \mathrm{He} /{ }^{4} \mathrm{He}$ ratios, from the stability of observed ${ }^{3} \mathrm{He} /{ }^{4} \mathrm{He}$ ratios versus the pressure of sample gas. ${ }^{3} \mathrm{He} /{ }^{4} \mathrm{He}$ ratios of volcanic gas samples, which were measured under optimized conditions and calibrated with the helium standard gas (HESJ) ${ }^{[3]}$, were consistent with those measured by a magnet-sector type mass spectrometer within analytical errors.

[1] M. Toyoda et al. (2003), J. Mass Spectrom. 38, 11251142. [2] S. Shimma et al. (2010), Anal. Chem. 82, 8456-8463. [3] J. Matsuda et al. (2002), Geochem. J. 36, 191-195. 